Letter

\title{
Broadband Electrical Sensing of a Live Biological Cell with In Situ Single-Connection Calibration
}

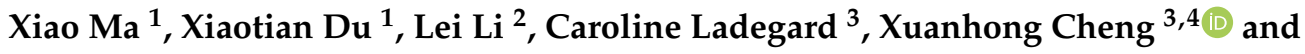 \\ James C. M. Hwang ${ }^{5, *}$ \\ 1 Electrical and Computer Engineering, Lehigh University, Bethlehem, PA 18015, USA; \\ xim214@lehigh.edu (X.M.); xid415@lehigh.edu (X.D.) \\ 2 Electrical and Computer Engineering, Cornell University, New York, NY 14850, USA; 11886@cornell.edu \\ 3 Bioengineering, Lehigh University, Bethlehem, PA 18015, USA; cal618@lehigh.edu (C.L.); \\ xuc207@lehigh.edu (X.C.) \\ 4 Materials Science and Engineering, Lehigh University, Bethlehem, PA 18015, USA \\ 5 Materials Science and Engineering, Cornell University, New York, NY 14850, USA \\ * Correspondence: jch263@cornell.edu
}

Received: 16 June 2020; Accepted: 7 July 2020; Published: 9 July 2020

\begin{abstract}
Single-connection in situ calibration using biocompatible solutions is demonstrated in single-cell sensing from 0.5 to $9 \mathrm{GHz}$. The sensing is based on quickly trapping and releasing a live cell by dielectrophoresis on a coplanar transmission line with a little protrusion in one of its ground electrodes. The same transmission line is used as the calibration standard when covered by various solutions of known permittivities. The results show that the calibration technique may be precise enough to differentiate cells of different nucleus sizes, despite the measured difference being less than $0.01 \mathrm{~dB}$ in the deembedded scattering parameters. With better accuracy and throughput, the calibration technique may allow broadband electrical sensing of live cells in a high-throughput cytometer.
\end{abstract}

Keywords: biological cells; biosensors; microwave measurement; calibration; scattering parameters

\section{Introduction}

With emerging broadband electrical sensing of a single biological cell [1], fast, accurate, and in situ broadband electrical calibration is needed for incorporating the sensing technique in a high-throughput cytometer [2]. In particular, the calibration is needed for deembedding the measured scattering $(S)$ parameters to reference planes as close to the cell as possible [3-5]. However, traditional coaxial or on-wafer calibration based on short-open-load-through [6], load-reflect-match [7], and series-resistor [8] standards requires measurement connections which are different from those used in cell sensing, making traditional calibration impractical in a cytometer. Additionally, reconnection errors introduced by moving probes or exchanging standards [9] are significant for single-cell sensing, which requires changes in the $S$ parameters to be measured with a precision better than $0.01 \mathrm{~dB}$. In a cytometer with probes fixed at the cell suspension, switches are needed to reconnect the network analyzer to traditional co-axial or on-wafer standards. This not only introduces reconnection errors, but also lowers the precision by moving the reference plane farther away from the probe tip to the switch. To overcome the difficulty of traditional calibration techniques, we developed a single-connection calibration technique using various liquid standards and validated it for liquid sensing [10]. The accuracy of the novel technique is comparable to traditional calibration techniques. This paper expands on [10] mainly by applying the calibration technique to cell sensing instead of liquid sensing.

Traditional broadband electrical sensing techniques [3-5] typically use uniform transmission lines as calibration standards before sensing unknown liquids or randomly located cells [1,11]. However, 
they are not suitable for sensing a precisely located cell. By contrast, the present technique is based on a coplanar waveguide (CPW) transmission line that is uniform except for a little protrusion in one of its ground electrodes (Figure 1). The CPW, with such a defected ground, can double as the calibration standard when covered by different liquids. This is because the protrusion is so little that, although it can perturb the local field sufficiently to trap a cell at its tip by dielectrophoresis (DEP) [12], it does not disturb significantly the overall characteristics of the CPW. Note that the protrusion of $6 \mu \mathrm{m}$ is smaller than one-thousandth of the wavelength between 0.5 and $5 \mathrm{GHz}$. In fact, the reflection coefficient $\left|S_{11}\right|$ is below $-10 \mathrm{~dB}$ and the transmission coefficient $\left|S_{21}\right|$ is over $-2.5 \mathrm{~dB}$ between 0.5 and $9 \mathrm{GHz}$ for a centimeter-long CPW, even when its $200 \mu \mathrm{m}$ long center section around the protrusion is covered by deionized (DI), sucrose, or Roswell Park Memorial Institute (RPMI) 1640 solutions (Figure 2) [13].

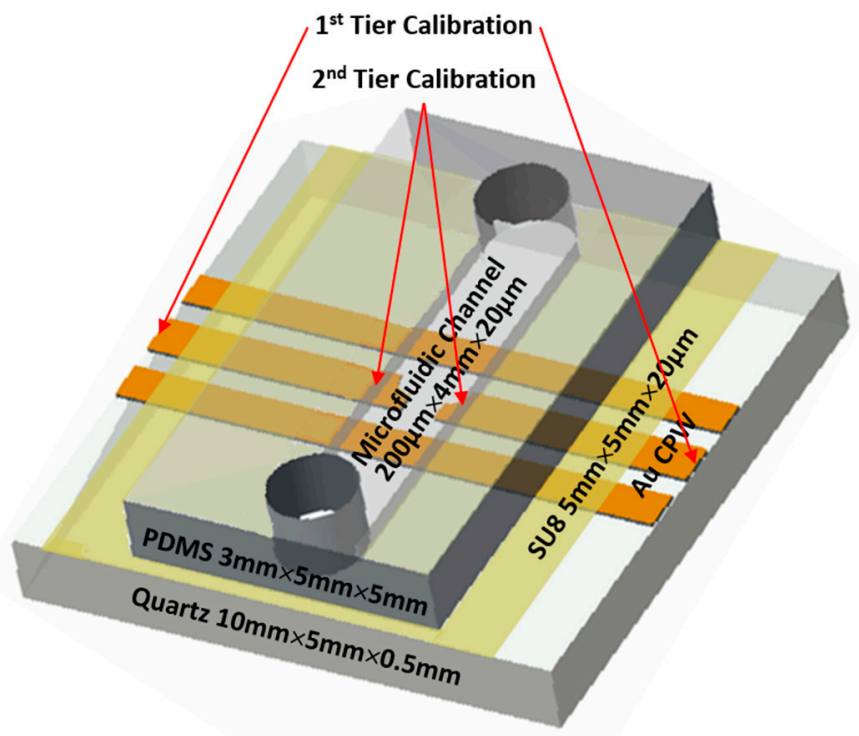

(a)

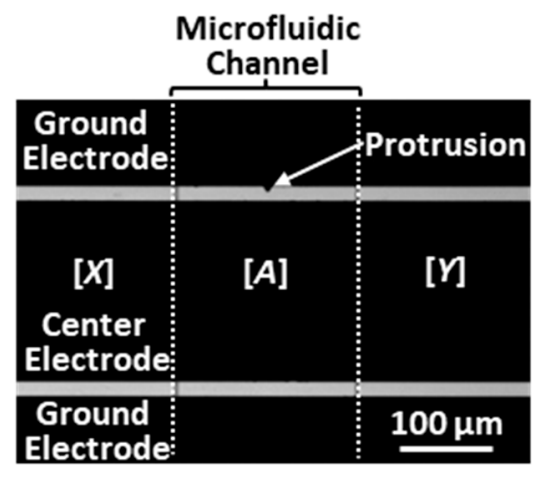

(b)

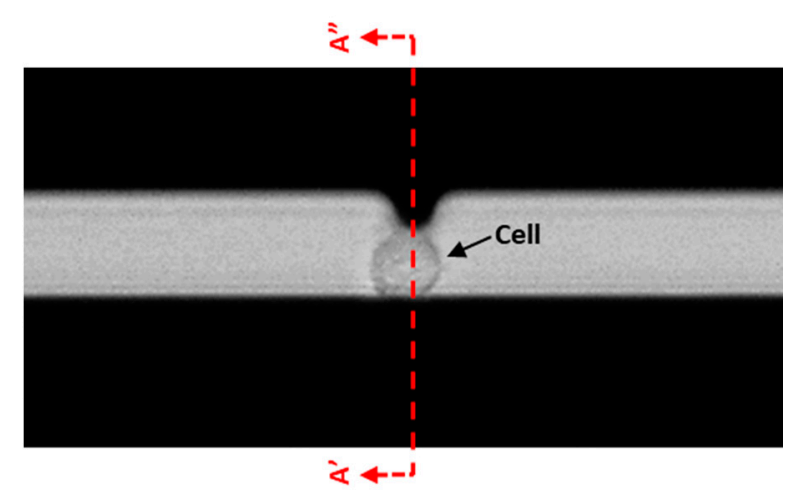

(c)

Figure 1. (a) Schematic illustration of the test chip comprising a microfluidic channel intersecting a coplanar waveguide (CPW) at a right angle. (b) Micrograph showing one of the ground electrodes of the CPW has a protrusion in the middle. (c) High-magnification micrograph showing a cell trapped by dielectrophoresis (DEP) at the tip of the protrusion. 


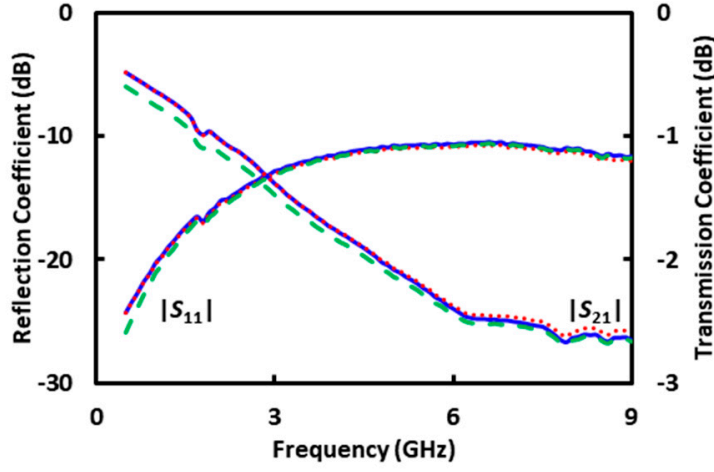

(a)

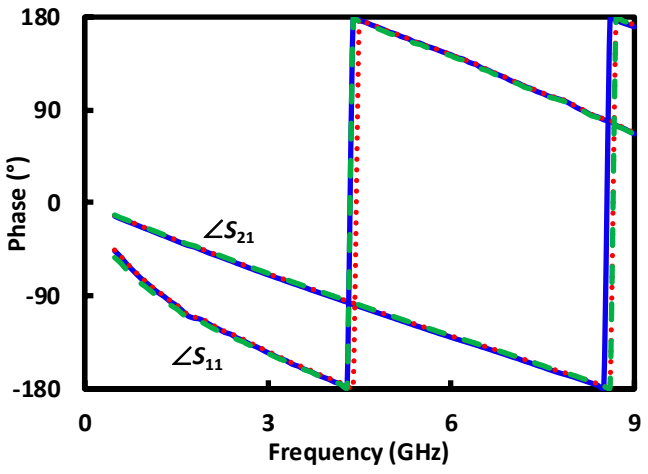

(b)

Figure 2. (a) Magnitude and (b) phase of measured $S$ parameters of the centimeter-long CPW with the microfluidic channel filled with DI (-), sucrose ( $\cdots)$, or RPMI (- - -) solutions.

The precision of the present calibration technique was tested on different cells from the same line, which were chemically treated to alter their nucleus size [14]. The test utilizes the capacity of the microwave signal to noninvasively sense subtle changes inside a cell [1]. Morphological changes of the cell nucleus are commonly used markers in cancer cytology for screening, diagnostics, and prognostics [15]. Analysis of nuclear morphology is critical to identification of precancerous and cancerous cells. Currently, nuclear morphological changes are often determined by fluorescence microscopy, although it requires labeling and, hence, is invasive [16]. Label-free electrical sensing can not only increase the speed and accuracy of cancer diagnosis over label-dependent optical techniques but can also enable real-time dynamic monitoring of the nucleus for fundamental understanding of cell development and malignancy progression.

In the following, Section 2 describes the experimental preparation, including the design of the test chip and the preparation of cells and liquid standards. Section 3 briefly reviews the calibration technique, leaving the details to [10]. Using the calibration technique, the resulted single-cell characteristics are presented and discussed in Section 4.

\section{Experimental Preparation}

\subsection{Test Chip Design}

Similar to [13], Figure 1 illustrates the present test chip, which is based on a microfluidic channel overlaying a CPW at $90^{\circ}$. The microfluidic channel is $200 \mu \mathrm{m}$ long, $4 \mathrm{~mm}$ wide, and $20 \mu \mathrm{m}$ high, with its length and width defined along the same directions as the CPW. The microfluidic channel is formed between SU8 walls and a polydimethylsiloxane (PDMS) cover. Both the SU8 and the PDMS are $5 \mathrm{~mm}$ long and $5 \mathrm{~mm}$ wide. The SU8 is $20 \mu \mathrm{m}$ thick. The PDMS is $3 \mathrm{~mm}$ thick to allow $250 \mu \mathrm{m}$ diameter inlet and outlet tubes to be inserted for the microfluidic channel. The CPW is fabricated on a $0.5 \mathrm{~mm}$ thick quartz substrate with $1 \mathrm{~cm}$ long and $200 \mu \mathrm{m}$ wide gold lines that are $0.5 \mu \mathrm{m}$ thick. The lines are generally spaced $16 \mu \mathrm{m}$ apart, except for one of the ground lines which has a $6 \mu \mathrm{m}$ long protrusion to reduce the spacing to $10 \mu \mathrm{m}$. As a result, the electric field is enhanced at the tip of the protrusion for trapping of a cell of approximately $10 \mu \mathrm{m}$ in diameter by DEP. When trapped, a cell shunts the center line to the ground line (Figure 1), which perturbs the measured $S$ parameters of the CPW.

\subsection{Electrical Measurement Setup}

Figure 3a is a photograph of the electrical measurement setup. It is based on a microwave probe station (homemade) on top of an inverted fluorescence microscope (Nikon, Eclipse Ti-E, Tokyo, Japan). The microscope has a video camera (three-color, 100 frames/s) to allow automated optical microscopy and electrical measurement simultaneously [17]. The test chip is a pair of wafer probes 
(Cascade Microtech, ACP40 GSG, Beaverton, Oregon, USA), which are connected to a vector network analyzer (VNA, Keysight Technologies, E5080A, Santa Rose, California USA) for 2-port S-parameter measurements. Rapidly successive measurements are performed in about one minute by programing the power and frequency of the same VNA through a sequence of DEP trapping (0 dBm, $10 \mathrm{MHz})$, electrical sensing ( $-18 \mathrm{dBm}, 0.5-9 \mathrm{GHz})$, DEP releasing ( $3 \mathrm{dBm}, 10 \mathrm{kHz})$, and electrical sensing again after the cell is released [18]. The power and frequency are carefully chosen for each function based on previous experiments. For example, the cell is released by not only lowering the frequency to switch from positive DEP to negative DEP, but also by doubling the power to compensate for the lower value of the Clausius-Mossotti factor at the lower frequency [12]. The sensing power level is orders-of-magnitude lower than that required for reversible electroporation, let alone heating or otherwise affecting the vitality of the cell [17]. Because the VNA can quickly switch between trapping and sensing, $S$ parameters can be measured with the cell remaining trapped and without the interference of the DEP signal. The measured $S$ parameters at the probe tips $(1 \mathrm{~cm}$ apart) are deembedded to the edges of the microfluidic channel (200 $\mu \mathrm{m}$ wide) using liquid standards as described in Section 3.

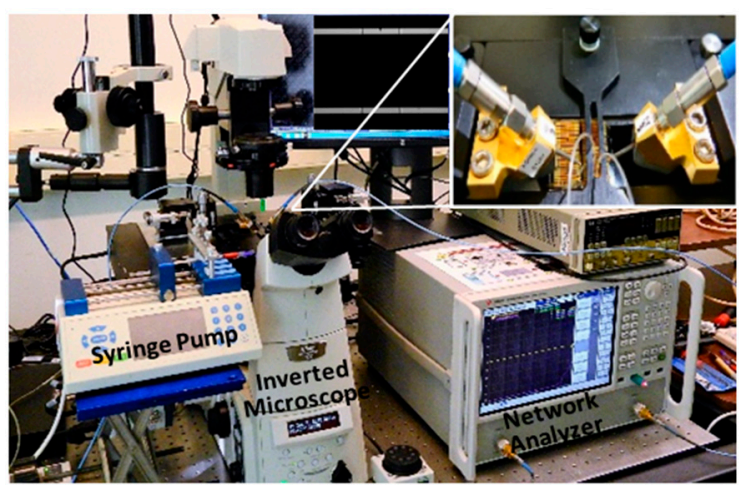

(a)

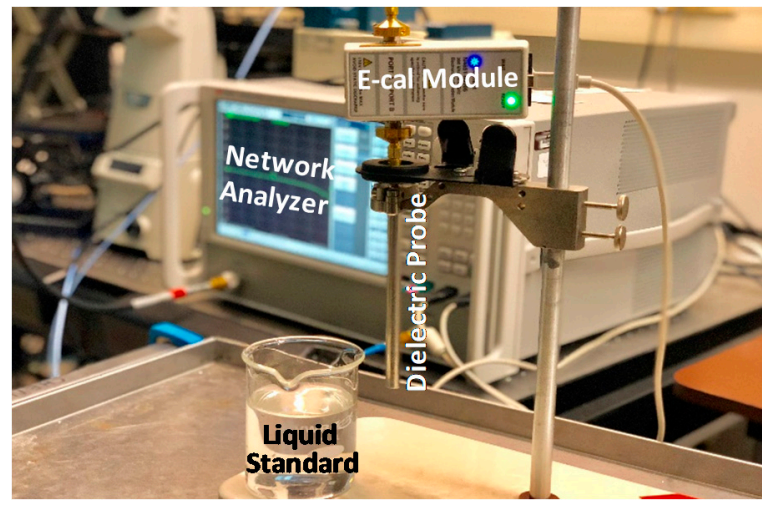

(b)

Figure 3. Photographs of measurement setup for (a) $S$ parameters of the test chip and (b) permittivity of the liquid standard using the same vector network analyzer.

\subsection{Liquid Standards Preparation}

For liquid standards, DI water, sucrose solution and RPMI-1640 culture medium are chosen for their compatibility with the test chip and cells. The isotonic sucrose solution contains sucrose $(8.5 \%)$ and dextrose $(0.3 \%)$ to keep the cells alive. The RPMI-1640 medium is from Sigma-Aldrich and is mixed with fetal bovine serum (10\%), penicillin (100 units/mL), and streptomycin $(100 \mu \mathrm{g} / \mathrm{mL})$. The standards are freshly made and characterized on the day of cell sensing. Figure $3 b$ shows that the liquid standards are characterized by using a dielectric probe (Keysight Technologies 85070E) with the same VNA used for cell sensing. Although liquid characterization involves a 1-port measurement instead of the 2-port measurement used for cell sensing, it is also based on in situ single-connection calibration using a Keysight Technologies N4691-60006 E-Cal module. During the calibration, the module is set to "short" and "open." After the calibration, the module is set to "through" for liquid characterization. Figure 4 shows that the liquid standards have similar permittivities $\varepsilon=\varepsilon^{\prime}-j \varepsilon^{\prime \prime}$, except $\varepsilon^{\prime \prime}$ for the RPMI solution is much higher below $1 \mathrm{GHz}$ due to its higher ionic content. The DI water result is in agreement with the literature [19].

\subsection{Cell Preparation Protocol}

To demonstrate the feasibility of in situ single-connection calibration, Jurkat T-lymphocytes human cells are used due to their large diameter $(\sim 10 \mu \mathrm{m})$, simple structure (with a relatively large nucleus) and non-adherent nature. These cells, which are obtained from ATCC (commercial cells lines), are cultured in the RPMI solution under $37^{\circ} \mathrm{C}$ and $5 \% \mathrm{CO}_{2}$. To reduce the nucleus size by approximately 30\% [14], 
some cells undergo additional treatment by a solution of staurosporine $(460 \mu \mathrm{g} / \mathrm{mL})$ in dimethyl sulfoxide up to three hours [20]. Cells without this additional treatment are used as a control. The cells, treated or not, are washed twice then re-suspended in the sucrose solution and diluted $\left(3 \times 10^{6} \mathrm{cell} / \mathrm{mL}\right)$ for electrical measurement. A separate experiment using Trypan blue dye confirms that more than half of cells are vital after ten hours [1]. For electrical measurement, cell suspensions are flown through the microfluidic channel on the test chip. The flow rate is controlled by a syringe pump at $0.1 \mu \mathrm{L} / \mathrm{min}$. For calibration, cell suspensions are sequentially replaced by sucrose, RPMI, and DI solutions without lifting the probes or otherwise changing the electrical connection. The last flow of DI water cleans the microfluidic channel allowing it to be reused.

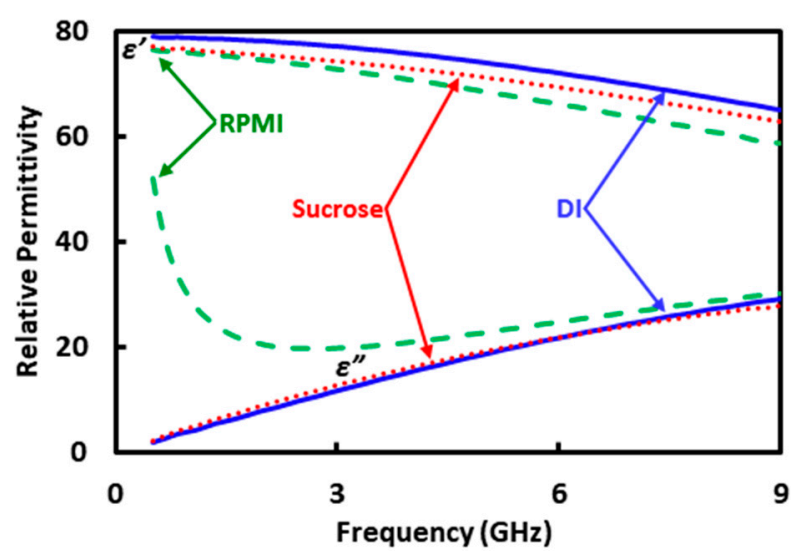

Figure 4. Real and imaginary parts of measured permittivities, $\varepsilon^{\prime}$ and $\varepsilon^{\prime \prime}$, of DI (-), sucrose ( $\left.\cdots\right)$, and RPMI (- - ) solutions.

\section{Calibration Technique and Standards}

For 2-port in situ single-connection calibration, cascading $T$ matrixes $X$ and $Y$ are used to represent the error matrixes at each port as illustrated in Figure $1 \mathrm{~b}$. The $X$ and $Y$ matrixes can then be used to relate the matrix $A$ of the CPW in the microfluidic channel to the measured matrix $M$ of the entire CPW:

$$
M=X A Y ; A=X^{-1} M Y^{-1}
$$

All the $T$ matrixes $X, Y, A$, and $M$ can be related to their respective $S$ matrixes in a standard form:

$$
T=\frac{1}{S_{21}}\left[\begin{array}{cc}
S_{12} \cdot S_{21}-S_{11} \cdot S_{22} & S_{11} \\
-S_{22} & 1
\end{array}\right]
$$

Following [10], the deembedding procedure can be simplified by setting $X$ in the form [8]

$$
X=r\left(\begin{array}{ll}
1 & a \\
b & c
\end{array}\right)
$$

where $r=(c-a b)^{-1 / 2}$. Once $X$ is known, $Y$ can be calculated from $A^{-1} X^{-1} M$.

To solve for $a, b$, and $c$, at least two measurements using two different liquid standards $\left(M_{1}=\right.$ $X A_{1} Y$ and $M_{2}=X A_{2} Y$ ) can be used to form the following four independent equations:

$$
\begin{aligned}
& -T_{21}^{A} a+T_{12}^{M} b+T_{11}^{M}-T_{11}^{A}=0 \\
& \left(T_{11}^{M}-T_{22}^{A}\right) a+T_{12}^{M} c-T_{12}^{A}=0 \\
& \left(T_{22}^{M}-T_{11}^{A}\right) b-T_{21}^{A} c+T_{12}^{A}=0 \\
& T_{21}^{M} a-T_{12}^{A} b-\left(T_{22}^{M}-T_{22}^{A}\right) c=0
\end{aligned}
$$


where $T^{A}=A_{2} A_{1}^{-1}$ and $T^{M}=M_{2} M_{1}^{-1}$. Since there are only three unknowns, the fourth equation can be used for checking consistency. In addition, more equations from measurements of more than two standards can ensure convergence in the iterative solution of these nonlinear equations even with poor initial values. For the results described in Section 4, three standards of DI, sucrose, and RPMI solutions are used. Detailed derivations, explanations, and examples of this calibration technique can be found in [10].

The standards such as $A_{1}$ and $A_{2}$ are generated by using the electromagnetic simulator HFSS with the structure of the microfluidic channel and the permittivities from Figure 4 . Figure 5 illustrates the simulated distribution of the electric field along the cross section through the protrusion in the ground electrode as indicated by $\mathrm{A}^{\prime}-\mathrm{A}^{\prime \prime}$ in Figure 1c, with DI water in the microfluidic channel. The simulation also generates the $S$ matrixes for the $200 \mu \mathrm{m}$ long CPW section covered with DI, sucrose, and RPMI solutions, respectively, as shown in Figure 6. It can be seen that although the characteristics with DI and sucrose are similar, the characteristics with RPMI are significantly different from that with DI or sucrose. (The same difference appears in measured $S$ parameters of the centimeter-long CPW characteristics as shown in Figure 2, although it is not as prominent because the $200 \mu \mathrm{m}$ long CPW section in the microfluidic channel is a small fraction of the centimeter-long total length.) Therefore, in practice, calibration can be performed with only DI and RPMI, or only sucrose and RPMI, with the third solution used to check for consistency or to expedite convergence as discussed earlier.

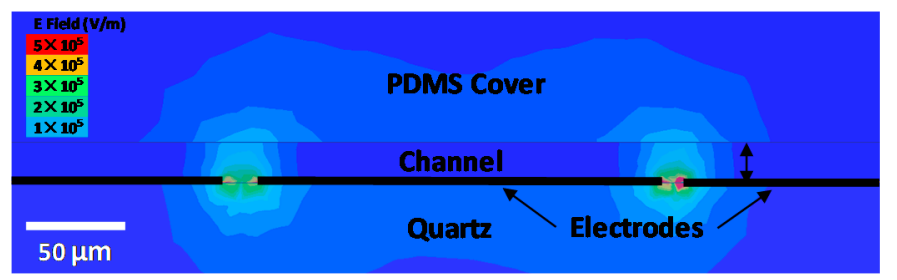

Figure 5. Distribution of electric field simulated at $5 \mathrm{GHz}$ along the cross section through the protrusion in the ground electrode as indicated by $\mathrm{A}^{\prime}-\mathrm{A}^{\prime \prime}$ in Figure 1c, with DI water in the microfluidic channel. The field is stronger on the right side because of the protrusion.

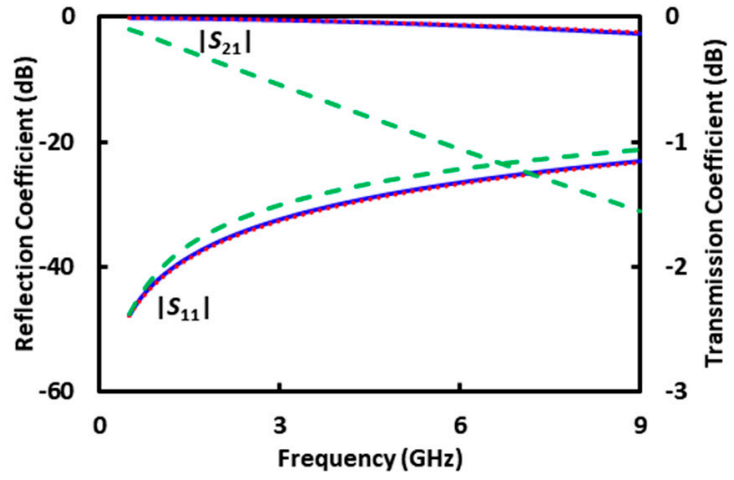

(a)

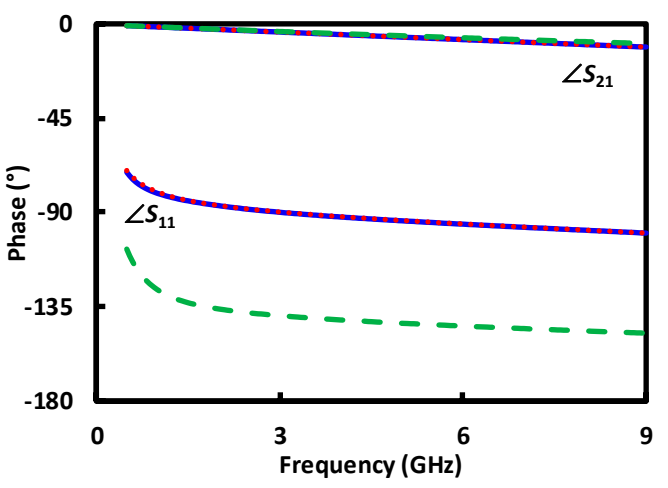

(b)

Figure 6. Simulated (a) magnitude and (b) phase of $S$ parameters of the $200 \mu \mathrm{m}$ long CPW section under DI (-), sucrose $(\cdots)$, or RPMI (- - ) solutions.

The $S$ matrixes of Figure 6 can be converted to the $T$ matrixes $A_{D I}, A_{S U C R O S E}$, and $A_{R P M I}$ by Equation (2). Presently, finite-element simulation [21,22] is necessary because a relatively thin $(20 \mu \mathrm{m})$ microfluidic channel is used to facilitate cell trapping, so that the field penetrates into the PDMS cover as shown in Figure 5. This multi-dielectric channel precludes analytical modeling such as conformal mapping $[4,23,24]$.

To check for self-consistency, Figure 7 shows the deembedded $S$ parameters of the $200 \mu \mathrm{m}$ CPW section under DI, sucrose or RPMI. The $S$ parameters are deembedded from the as-measured 
$S$ parameters shown in Figure 2 using the calibrated error matrixes $X^{-1}$ and $Y^{-1}$ as described in the above. It can be seen that the deembedded $S$-parameter magnitudes agree with the simulated values of Figure 6a, whereas the deembedded $S$-parameter phases are too small and noisy to be useful as seen in previous experiment [13] and analysis [25].

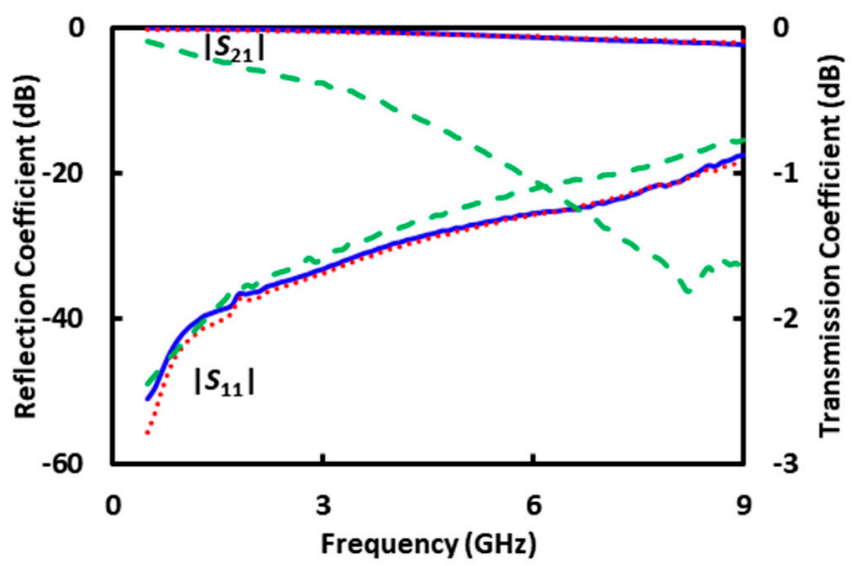

Figure 7. Deembedded magnitude of measured $S$ parameters for the $200 \mu \mathrm{m}$ long CPW section under DI (-), sucrose $(\cdots)$, or RPMI (- - ) solutions.

\section{Result and Discussion}

The $60 \mathrm{~dB}$ scale of Figure 7 is so coarse that the deembedded $S$ parameters of the CPW section under a sucrose-filled microfluidic channel are indistinguishable whether a cell is trapped or not. The two cases are difficult to distinguish because the impedance of a cell is on the order of $1 \mathrm{M} \Omega$ and its shunting effect is on the order of $0.01 \mathrm{~dB}$ [13]. To make the difference more visible, the difference is replotted by itself in Figure 8 as

$$
\begin{aligned}
& \Delta\left|S_{11}\right|=10 \log \left(\left|S_{11}\right| \mathrm{w} / \text { cell }\right)-10 \log \left(\left|S_{11}\right| \mathrm{w} / \text { o cell }\right) \\
& \Delta\left|S_{21}\right|=10 \log \left(\left|S_{21}\right| \mathrm{w} / \text { cell }\right)-10 \log \left(\left|S_{21}\right| \mathrm{w} / \text { o cell }\right) .
\end{aligned}
$$

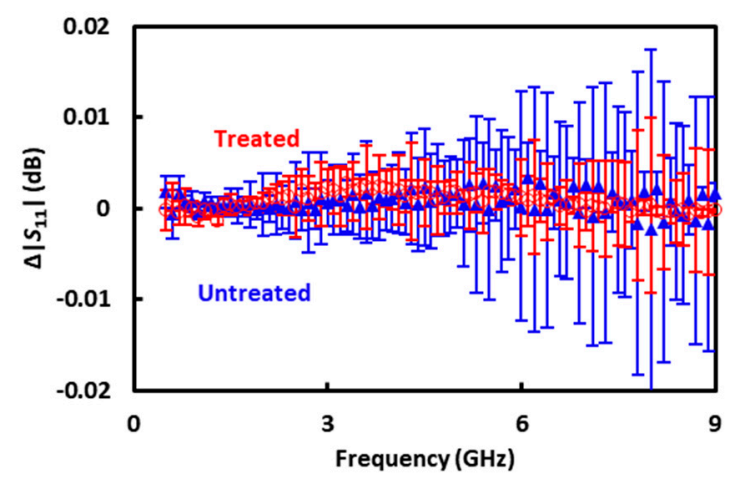

(a)

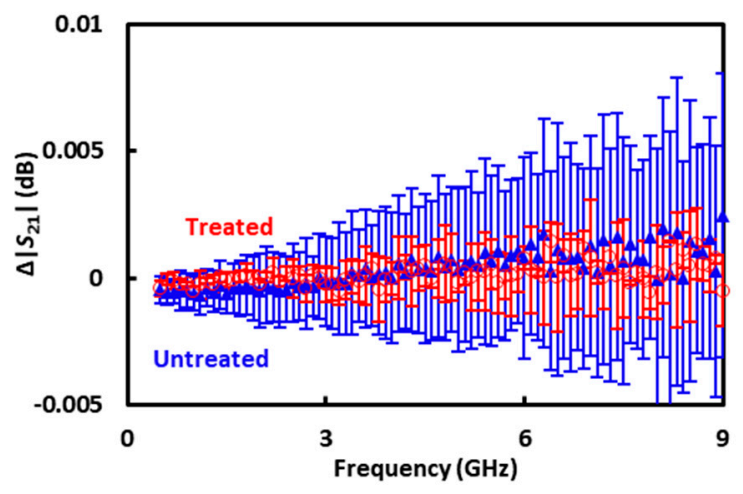

(b)

Figure 8. (a) $\Delta\left|S_{11}\right|$ and (b) $\Delta\left|S_{21}\right|$ measured on treated $(\bigcirc)$ and untreated ( $\mathbf{\Delta}$ ) cells individually.

Additionally, averages and standard deviations of $\Delta\left|S_{11}\right|$ and $\Delta\left|S_{21}\right|$ of repeated measurements are evaluated for treated and untreated cells, respectively. Altogether the measurements are repeated nine times on three treated cells and six untreated cells, with each cell measured only once. In general, whether a cell is treated or not, $\Delta\left|S_{21}\right|$ increases with increasing frequency and $\Delta\left|S_{21}\right|<\Delta\left|S_{11}\right|$. This is consistent with the theoretical analysis [25], independent of the calibration technique. 
To make the difference between treated and untreated cells even more visible, Figure 9 plots the average $\Delta\left|S_{11}\right|$ and $\Delta\left|S_{21}\right|$ on an expanded vertical scale. Despite the noises, average $\Delta\left|S_{11}\right|$ and $\Delta\left|S_{21}\right|$ of treated cells appear smaller than that of untreated cells. This trend seems reasonable considering that in terms of permittivity, the cytoplasm is closer to the sucrose solution than is the nucleus [26]. Therefore, with a smaller nucleus, the treated cells would be more similar to the sucrose solution they displace in the trap than the untreated cells would. However, this trend is opposite of that extracted by using conventional on-wafer short-open-load-through calibration standards [14]. Without systematic investigation, it is presently difficult to determine which calibration technique is more reliable for sensing the nucleus size. The contribution of this paper is mainly in demonstrating another calibration technique that can be conveniently incorporated into a cytometer. Much more work is needed to demonstrate its validity and to improve its accuracy. For example, more sets of treated and untreated cells should be measured in the future with improved accuracy and throughput. This would allow more statistical results including the percentage of correctly classified cells to be presented.

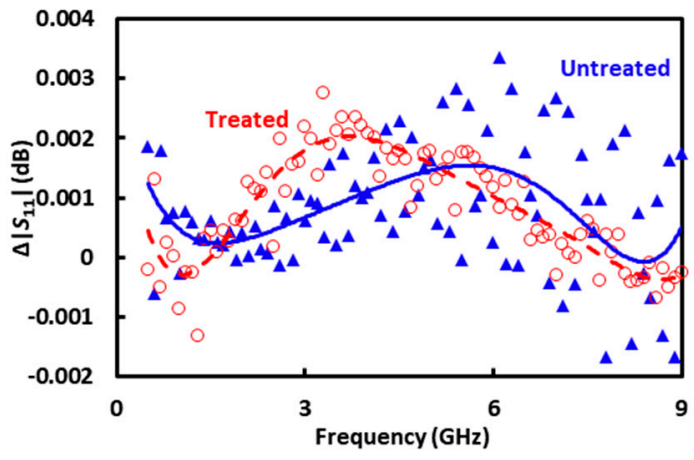

(a)

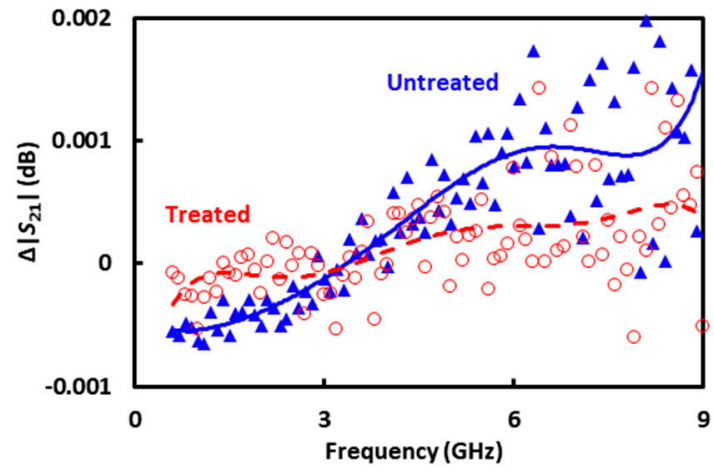

(b)

Figure 9. Average (a) $\Delta\left|S_{11}\right|$ and (b) $\Delta\left|S_{21}\right|$ measured on treated ( $\left.\bigcirc\right)$ and untreated ( $\left.\mathbf{\Delta}\right)$ cells. Trend lines by 6th-order polynomial fitting are shown to aid visibility.

Presently, three liquid standards are used in the calibration to ensure convergence in the iterative solution of Equations (4)-(7). When only two standards are used, the deembedded $\left|S_{21}\right|$ as shown in Figure 7 can exceed $0 \mathrm{~dB}$ at some frequencies, which is obviously unreasonable. The slow-wave effect of these solutions allows the $200 \mu \mathrm{m}$ wide microfluidic channel to significantly perturb the characteristics of the $1 \mathrm{~cm}$ long CPW. By contrast, air is not used as a standard because with the microfluidic channel empty, its $200 \mu \mathrm{m}$ length is too short to significantly perturb the CPW characteristics. Moreover, under air, more field radiates outside the microfluidic channel resulting in greater simulation uncertainty.

Presently, we use two-tier calibration mainly because the liquid standards have rather similar permittivities. As illustrated in Figure 1a, we used first-tier calibration by on-wafer calibration standards to deembed the measured $S$ parameters from the VNA to the probe tips which are $1 \mathrm{~cm}$ apart. We then used second-tier calibration by liquid standards to further deembed the $S$ parameters from the probe tips to the edges of the microfluidic channel, which are $200 \mu \mathrm{m}$ apart. Had the liquid standards been more different, we could use them for single-tier calibration from the VNA directly to the microfluidic channel, making it more suitable for the eventual use in a cytometer. We can improve the present calibration technique by adding nonaqueous calibration standards, such as methanol or ethanol, whose permittivity differs significantly from that of water especially at high frequencies. However, we must consider their poisonous effect on live cells.

With improved calibration accuracy to deembed the $S$ parameters to the edges of the microfluidic channel, the channel width can be shortened to enhance the contrast of $\Delta\left|S_{11}\right|$ and $\Delta\left|S_{21}\right|$. This should, in turn, increase the sensitivity of single-cell sensing to above $0.01 \mathrm{~dB}$. However, if the microfluidic 
channel is too short compared to the total length of the $\mathrm{CPW}$, the perturbation to its characteristics by different liquids is reduced, thereby increasing the calibration error.

\section{Conclusions}

For the first time, in situ single-connection calibration by multiple liquid standards is demonstrated in broadband sensing of a live cell. The sensing is based on quickly trapping and releasing the cell by DEP on a CPW with a little protrusion in one of its ground electrodes, as well as using the same CPW as the calibration standard when covered by different liquids. The results show that the calibration technique may be precise enough to differentiate cells of different nucleus sizes. With further improvement in accuracy and throughput, the technique may allow broadband electrical sensing of a single cell in a high-throughput cytometer.

Author Contributions: Conceptualization, J.C.M.H. and X.C.; methodology, X.M., X.D. and L.L.; software, X.M.; validation, X.M. and X.D.; formal analysis, X.M. and X.D.; investigation, X.M. and X.D.; resources, J.C.M.H. and X.C.; data curation, X.M., X.D. and C.L.; writing—original draft preparation, X.M.; writing—review and editing, J.C.M.H.; visualization, X.M.; supervision, J.C.M.H. and X.C.; project administration, J.C.M.H. and X.C.; funding acquisition, J.C.M.H. and X.C. All authors have read and agreed to the published version of the manuscript.

Funding: This research was supported in part by the U.S. Department of Defense, Army Research Office (Grant W911NF-14-1-0665), Air Force Office of Scientific Research (Grant FA9550-16-1-0475), and U.S. National Science Foundation (Grant ECCS-1809623).

Conflicts of Interest: The authors have no conflict of interest.

\section{References}

1. Ning, Y.; Multari, C.; Luo, X.; Palego, C.; Cheng, X.; Hwang, J.C.; Denzi, A.; Merla, C.; Apollonio, F.; Liberti, M. Broadband electrical detection of individual biological cells. IEEE Trans. Microw. Theory Tech. 2014, 62, 1905-1911. [CrossRef]

2. Chien, J.-C.; Ameri, A.; Yeh, E.-C.; Anwar, M.; Killilea, A.N.; Niknejad, A.M. A high-throughput flow cytometry-on-a-CMOS platform for single-cell dielectric spectroscopy at microwave frequencies. Lab Chip 2018, 18, 2065-2076. [CrossRef] [PubMed]

3. Grenier, K.; Dubuc, D.; Poleni, P.-E.; Kumemura, M.; Toshiyoshi, H.; Fujii, T.; Fujita, H. Integrated Broadband Microwave and Microfluidic Sensor Dedicated to Bioengineering. IEEE Trans. Microw. Theory Tech. 2009, 57, 3246-3253. [CrossRef]

4. Booth, J.C.; Orloff, N.D.; Mateu, J.; Janezic, M.; Rinehart, M.; Beall, J.A. Quantitative Permittivity Measurements of Nanoliter Liquid Volumes in Microfluidic Channels to $40 \mathrm{GHz}$. IEEE Trans. Instrum. Meas. 2010, 59, 3279-3288. [CrossRef]

5. Liu, S.; Ocket, I.; Barmuta, P.; Markovič, T.; Lewandowski, A.; Schreurs, D.; Nauwelaers, B. Broadband dielectric spectroscopy calibration using calibration liquids with unknown permittivity. In Proceedings of the 84th ARFTG Microwave Measurement Conference, Boulder, CO, USA, 4-5 December 2014; pp. 1-5.

6. Padmanabhan, S.; Dunleavy, L.; Daniel, J.; Rodriguez, A.; Kirby, P. Broadband Space Conservative On-Wafer Network Analyzer Calibrations with More Complex Load and Thru Models. IEEE Trans. Microw. Theory Tech. 2006, 54, 3583-3593. [CrossRef]

7. Williams, D.; Marks, R. LRM probe-tip calibrations using nonideal standards. IEEE Trans. Microw. Theory Tech. 1995, 43, 466-469. [CrossRef]

8. Williams, D.F.; Walker, D.K. Series-Resistor Calibration. In Proceedings of the 50th ARFTG Conference Digest, Portland, OR, USA, 4-5 December 1997; pp. 131-137.

9. Williams, D.F.; Marks, R.B.; Davidson, A. Comparison of On-Wafer Calibrations. In Proceedings of the 38th ARFTG Conference Digest, San Diego, CA, USA, 5-6 December 1991; pp. 68-81.

10. Ma, X.; Orloff, N.D.; Little, C.D.; Long, C.J.; Hanemann, I.E.; Liu, S.; Mateu, J.; Booth, J.C.; Hwang, J.C.M. A Multistate Single-Connection Calibration for Microwave Microfluidics. IEEE Trans. Microw. Theory Tech. 2017, 66, 1099-1107. [CrossRef] 
11. Li, H.; Multari, C.; Palego, C.; Ma, X.; Du, X.; Ning, Y.; Buceta, J.; Hwang, J.C.M.; Cheng, X. Differentiation of live and heat-killed E. coli by microwave impedance spectroscopy. Sens. Actuators B Chem. 2018, 255, 1614-1622. [CrossRef]

12. Du, X.; Ma, X.; Li, H.; Li, L.; Cheng, X.; Hwang, J.C.M. Validation of Clausius-Mossotti Function in Wideband Single-Cell Dielectrophoresis. IEEE J. Electromagn. RF Microw. Med. Boil. 2019, 3, 127-133. [CrossRef]

13. Ma, X.; Du, X.; Li, H.; Cheng, X.; Hwang, J.C.M. Ultra-Wideband Impedance Spectroscopy of a Live Biological Cell. IEEE Trans. Microw. Theory Tech. 2018, 66, 3690-3696. [CrossRef]

14. Du, X.; Ladegard, C.; Ma, X.; Cheng, X.; Hwang, J.C.M. Ultra-wideband Electrical Sensing of Nucleus Size in a Live Cell. In Proceedings of the European Microwave Conference (EuMC), Paris, France, 1-3 October 2019; pp. 1-4.

15. Jevtić, P.; Edens, L.J.; Vuković, L.D.; Levy, D.L. Sizing and shaping the nucleus: Mechanisms and significance. Curr. Opin. Cell Boil. 2014, 28, 16-27. [CrossRef] [PubMed]

16. Al-Abbadi, M.A. Basics of cytology. Avicenna J. Med. 2011, 1, 18-28. [CrossRef] [PubMed]

17. Li, H.; Ma, X.; Du, X.; Li, L.; Cheng, X.; Hwang, J.C.M.; Xiao, M. Correlation between Optical Fluorescence and Microwave Transmission during Single-Cell Electroporation. IEEE Trans. Biomed. Eng. 2019, 66, 2223-2230. [CrossRef] [PubMed]

18. Du, X.; Ma, X.; Li, L.; Li, H.; Cheng, X.; Hwang, J.C. Ultra-wideband characterization, dielectrophoresis, and electroporation of a live biological cell using the same vector network analyzer. In Proceedings of the IEEE/MTT-S International Microwave Symposium-IMS, Philadelphia, PA, USA, 10-15 June 2018; pp. 1-4.

19. Buchner, R.; Barthel, J.; Stauber, J. The dielectric relaxation of water between $0{ }^{\circ} \mathrm{C}$ and $35^{\circ} \mathrm{C}$. Chem. Phys. Lett. 1999, 306, 57-63. [CrossRef]

20. Chowdhury, I.; Xu, W.; Stiles, J.K.; Zeleznik, A.; Yao, X.; Matthews, R.; Thomas, K.; Thompson, W.E. Apoptosis of rat granulosa cells after staurosporine and serum withdrawal is suppressed by adenovirus-directed overexpression of prohibition. Endocrinology 2007, 148, 206-217. [CrossRef] [PubMed]

21. Denzi, A.; Merla, C.; Palego, C.; Paffi, A.; Ning, Y.; Multari, C.R.; Cheng, X.; Apollonio, F.; Hwang, J.C.M.; Liberti, M. Assessment of Cytoplasm Conductivity by Nanosecond Pulsed Electric Fields. IEEE Trans. Biomed. Eng. 2015, 62, 1595-1603. [CrossRef] [PubMed]

22. Li, H.; Denzi, A.; Ma, X.; Du, X.; Ning, Y.; Cheng, X.; Apollonio, F.; Liberti, M.; Hwang, J.C.M. Distributed Effect in High-Frequency Electroporation of Biological Cells. IEEE Trans. Microw. Theory Tech. 2017, 65, 3503-3511. [CrossRef]

23. Simons, R.N. Coplanar Waveguide Circuits, Components, and Systems; Wiley: New York, NY, USA, 2001.

24. Ye, D.; Islam, S.; Yu, G.; Wang, P. A Single-Line Single-Channel Method with Closed-Form Formulas for the Characterization of Dielectric Liquids. IEEE Trans. Microw. Theory Tech. 2019, 67, 2443-2450. [CrossRef]

25. Ma, X.; Du, X.; Li, L.; Li, H.; Cheng, X.; Hwang, J.C.M. Sensitivity Analysis for Ultra-Wideband 2-Port Impedance Spectroscopy of a Live Cell. IEEE J. Electromagn. RF Microw. Med. Boil. 2020, 4, 37-44. [CrossRef]

26. Suzuki, Y.; Taki, M.; Saito, H.; Taguchi, T. Measurement of complex permittivity for biological cells by waveguide penetration method. In Proceedings of the 2009 International Symposium on Electromagnetic Compatibility, Kyoto International Conference Center, Tokyo, Japan, 20-24 July 2009; pp. 317-320.

(C) 2020 by the authors. Licensee MDPI, Basel, Switzerland. This article is an open access article distributed under the terms and conditions of the Creative Commons Attribution (CC BY) license (http://creativecommons.org/licenses/by/4.0/). 